\title{
Determining the association between dengue and social inequality factors in north-eastern Brazil: A spatial modelling
}

\author{
Damião da Conceição Araújo, ${ }^{1}$ Allan Dantas dos Santos, ${ }^{2}$ Shirley Verônica Melo Almeida Lima, ${ }^{3}$ \\ Andreia Centenaro Vaez, ${ }^{4}$ Jéssica Oliveira Cunha, ${ }^{4}$ \\ Karina Conceição Gomes Machado de Araújo ${ }^{5}$ \\ ${ }^{1}$ Health Sciences Graduate Program, Federal University of Sergipe; ${ }^{2}$ Nursing Postgraduate Program, \\ Federal University of Sergipe and Research Group in Public Health; ${ }^{3}$ Health Sciences Graduate Program, \\ Federal University of Sergipe and Research Group in Public Health; ${ }^{4}$ Nursing Postgraduate Program, \\ Federal University of Sergipe; ${ }^{5}$ Health Sciences Graduate Program and Graduate Program in Parasitic \\ Biology, Federal University of Sergipe, Brazil
}

\begin{abstract}
Dengue is a global public health problem. The Dengue Virus (DENV) serotypes are transmitted by an Aedes aegypti mosquito. Vector control is among the primary methods to prevent the disease, especially in tropical countries. This study aimed to analyze the spatial distribution of dengue and its relationship with social inequalities using spatial modelling. An ecological study with temporal and spatial analysis was conducted in the state of
\end{abstract}

Correspondence: Karina Conceição Gomes Machado, Post-Graduate Program in Health Sciences, Federal University of Sergipe, Av. Marechal Rondon, s/n, Rosa Elze, São Cristóvão, SE, 49100-000, Sergipe, Brasil.

E-mail: kkkaraujo2006@yahoo.com.br

Key words: Dengue; Spatial analysis; Time series studies; Brazil.

Acknowledgments: The Authors thank the State Secretary of Health of Sergipe for making the epidemiological data available and Coordination for the Improvement of Higher Education Personnel (CAPES)

Conflict of Interests: The authors declare no potential conflict of interests.

Ethical aspects: The research was approved by the Ethics Committee on Research with Human Beings of the Federal University of Sergipe, under opinion no. 3,324,305. Given the assumptions of research ethics, we maintained the confidentiality of data during processing. Analyses were performed anonymously; hence the Informed Consent Form was not necessary

Received for publication: 15 December 2019.

Accepted for publication: 15 April 2020.

(C) Copyright: the Author(s), 2020

Licensee PAGEPress, Italy

Geospatial Health 2020; 15:854

doi:10.4081/gh.2020.854

This article is distributed under the terms of the Creative Commons Attribution Noncommercial License (CC BY-NC 4.0) which permits any noncommercial use, distribution, and reproduction in any medium, provided the original author(s) and source are credited.
Sergipe, Northeast Brazil, over a period of 18 years. Spatial modelling was used to determine the influence of space on dengue incidence and social inequalities. The epidemic rates in 2008, 2012, and 2015 were identified. Spatial modelling explained $40 \%$ of the influence of social inequalities on dengue incidence in the state. The main social inequalities related to the occurrence of dengue were the percentage of people living in extreme poverty and inadequate sanitation. The epidemic situation even increased the risk of dengue in the population of the state of Sergipe. These results demonstrate the potential of spatial modelling in determining the factors associated with dengue epidemics and are useful in planning the intersectoral public health policies.

\section{Introduction}

Dengue is one of the vector-borne viral diseases that impacts the morbidity and mortality of the world population most, especially in tropical countries, requiring increasingly intensive efforts and investments from health services (Lutomiah et al., 2016). The disease is caused by four Dengue Virus (DENV) serotypes (DENV 1-4) belonging to the genus Flavivirus, family Flaviviridae, and is mainly transmitted by a female mosquito of the species Aedes aegypti (Restrepo et al., 2014). Emerging arboviruses transmitted by the same vector have been identified in the Americas, including chikungunya and Zika viruses (StewartIbarra et al., 2018).

An estimated 390 million dengue infections occur worldwide annually, of which 96 million exhibit clinical symptoms (WHO, 2015; Bhatt et al., 2013). In Brazil, dengue is becoming a serious public health problem (Araújo et al., 2017). Epidemics occur as a result of accelerated and unplanned urbanization, social commuting, increased international travel, and human activity in the environment that favours vector adaptation and proliferation (Guo et al., 2013), as well as the development of insecticide resistance (Moyes et al., 2017; Francis et al., 2017). Dengue is thus endemic in large areas of the tropical world where it has been shown to be impossible to effectively control. We have studied the disease and its transmission in the state of Sergipe, located in north-eastern Brazil.

Social exclusion and poverty increase the rates of social vulnerability. The exclusion or poor access to health services, adequate income, work, education, housing conditions, transporta- 
tion, sustainable environment, and social support networks lead to persistent social inequities in health, that is, the presence of groups that experience preventable, unfair, and unnecessary health problems (Frenk and Moon, 2013). The high percentage of Ae. aegypti mosquitoes is clearly related to dengue transmission, and the implementation of control and surveillance measures remains a challenge, especially in developing countries as there is no effective treatment or vaccination available (Christofferson and Mores, 2015). Therefore, vector control remains the most important method of preventing epidemics and severe forms of the disease (Zara et al., 2016).

The control strategy adopted in Brazil highlights the importance of vector control to prevent disease transmission, and is are performed by health professionals in collaboration with the population in the endemic areas. (Zara et al., 2016; Marcondes and Ximenes, 2016). Technological innovations have been suggested to aid in disease control such as risk mapping using Geographic Information Systems (GIS), which allows the identification of areas at risk of dengue (Zara et al., 2016). Spatiotemporal analysis can detect the areas with higher incidence of dengue and be used to better understand the dynamics of disease transmission in a given geographic area (Vazquez-Prokopec et al., 2010). By associating spatial data with epidemiological surveillance and socioeconomic indicators, control actions can be conducted in priority areas.

The persistent high incidence of dengue fever and the dearth of studies of this nature in the state of Sergipe prompted us to conduct this study to understand the dynamics of the disease over the years and verify its association with socioeconomic factors in order for managers and health professionals to develop the appropriate preventive measures. Thus, this study aimed to analyze the spatial distribution of dengue and its relationship with social inequalities using spatial modelling.

\section{Materials and Methods}

\section{Design and area of study}

An ecological study, with temporal and spatial analysis, was conducted from 2000 to 2018 . The units of analysis were the 75 municipalities of the state of Sergipe, which is located in the northeastern coast of Brazil (Figure 1). The state has 2,068,017 inhabitants and an area of 21,910,354 $\mathrm{km}^{2}$ (IBGE, 2017; Sergipe, 2011).

\section{Data source and definition of variables}

The sample consisted of dengue cases based on the clinical and epidemiological and laboratory criteria. Data from the Disease Information Notification System (SINAN), available from the Department of Health of Sergipe, were collected. The outcome (dependent variable) was the annual dengue incidence rates of dengue.

The following social indicators, which were collected from the 2010 Population Census and United Nations Development Program (UNDP, 2010), were used as independent variables: income; education; water supply; garbage collection; sanitary sewage; household occupation density; characteristics of households; social development index; the Theil's L Index and the Gini Index (two indices used to measure economic inequality); life expectancy at birth (in years); adult literacy rate; per capita income; extremely poor and poor; percentage of people vulnerable to poverty; and at-risk situations.

\section{Temporal and epidemiological analysis}

The annual dengue incidence rates were used to calculate the time trends in frequency of sick leave, with a model based on the assumption of a minimum number of points at which statistically

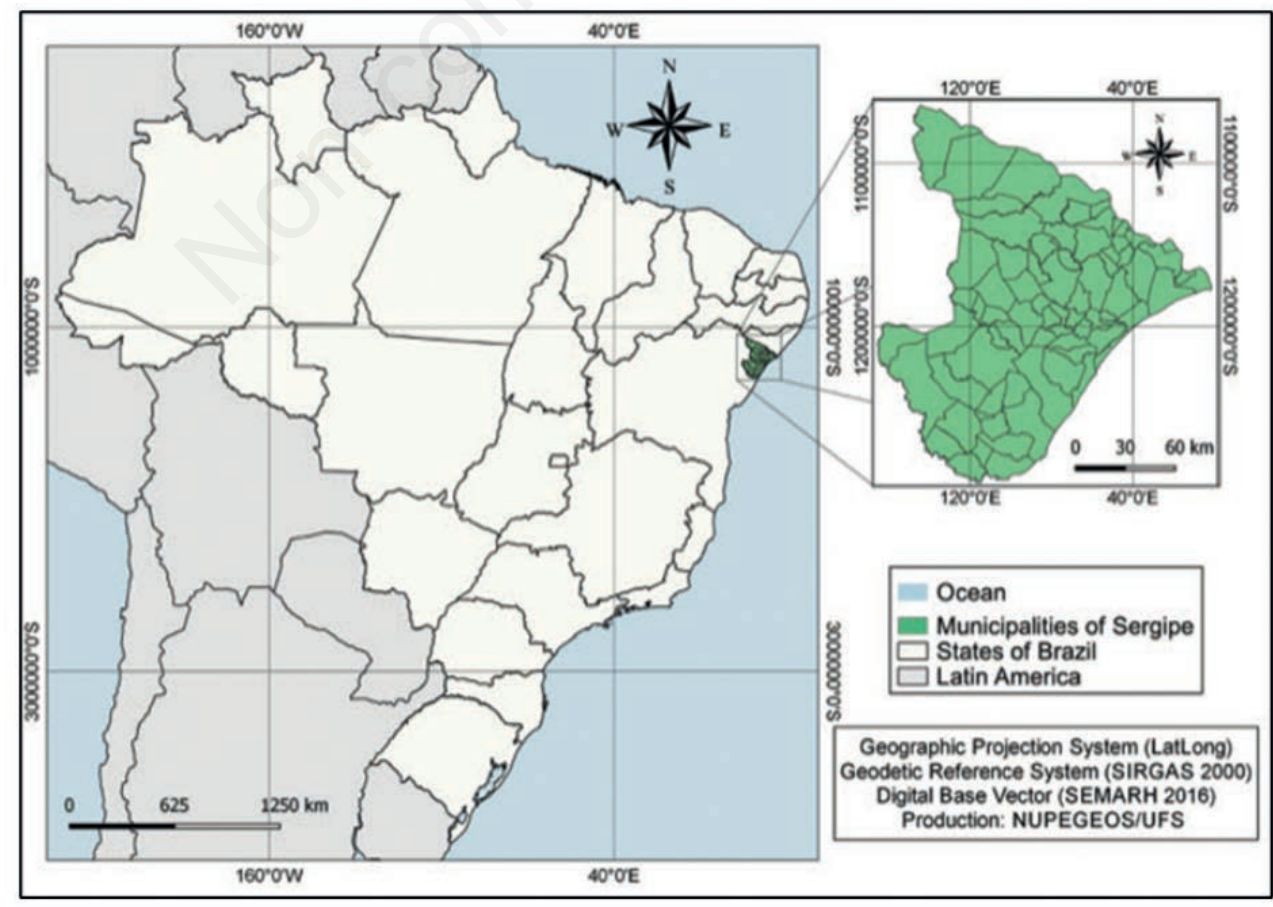

Figure 1. Delimitation of the study area. 
significant changes would occur (Kim et al., 2000). The JoinPoint Regression Program (Statistical Methodology and Applications Branch, Surveillance Research Program of the National Cancer Institute, Bethesda, MD, USA, version 4.5.0.1) was used to perform the analysis.

Segmented log-linear regression was used to describe the trend and identify changes in the pattern of disease distribution over the years, modelling linear segments joined by inflection points using the Monte Carlo permutation test. Moreover, for the minimum number of observations of a junction point for each end of the data, the value of 2 was standardized; and for the minimum number of observations between two joinpoints also, the value of 2 was standardized. With regard to the number of joinpoints in the trend, 0 was assigned as the minimum value and 3 as the maximum value. Thus, the average annual percentage change (AAPC) was calculated for the entire period. If the AAPC is positive and significant, then the trend is increasing. However, if the AAPC is negative and significant, the trend is decreasing. If there is no significance, the trend is stable (Kim et al., 2000).

An epidemiological analysis was performed using the BioEstat 5.0 program. The mean incidence rate was found to be correlated with the indicators of social inequality based on the Spearman's correlation coefficient, considering a significance level of 5\%.

\section{Spatial analysis}

The cartographic base of the state of Sergipe available on the electronic base of the Brazilian Institute of Geography and Statistics was used. The cartographic projection used was the SIRGAS 2000 Universal Reference System, and the georeferenced data were analyzed using TerraView, version 4.2.2 (National Institute for Space Research, SP, Brazil), QGIS, version 2.18.2 (Open Source Geospatial Foundation (https://www.osgeo.org/) and Geoda (https://geodacenter.github.io/).

The Global Empirical Bayesian Estimator was used to minimize the instability caused by the random fluctuation of cases, smoothing out the standardized rates by applying weighted averages, and creating a third corrected rate. The Empirical Bayesian Rate demonstrated the correction of the multiplicative rate equal to 100,000 taking into account the mid-period at-risk population (for the 2000-2018 period) and the total number of cases. In order to estimate the spatial variability in the data analysis, a proximity matrix was constructed; for neighbouring and neighbouring municipalities, the value 1 (one) was assigned, and for those without adjacent border geometries the value 0 (zero) was assigned (Brasil et al., 2007).

With the Bayesian rate created, the spatial autocorrelation was verified using Moran's Global I, which investigates whether the spatial distribution of the disease occurs randomly or follows a certain pattern. The method was also used to verify the spatial autocorrelation of socioeconomic indicators (only those that showed a positive correlation). The $I$ ranges from -1 to +1 . Values close to zero indicate spatial randomness, while those between 0 and +1 indicate positive spatial autocorrelation, and those between -1 and 0 negative spatial autocorrelation.

The Local Index of Spatial Association (LISA) version of the Local Moran's $I$ was used to map to indicate the areas at risk for dengue or with high dengue transmission, in order to compare the rates of each municipality with those of neighbouring municipalities and to verify spatial dependence (Druck et al., 2004). Thus, the following spatial quadrants were shown: Q1 (high/high) and Q2 (low/low), which indicate municipalities whose values were simi- lar to those of neighbouring municipalities and represent areas with positive spatial association aggregates, and Q3 (high/low) and Q4 (low/high), which indicate the transition areas with negative spatial association aggregates (Moran, 1948; Câmara and Monteiro, 2001).

We also used the Conditional AutoRegressive (CAR) linear spatial regression model to verify the spatial dependence of the dependent variable on a single parameter, considering that the spatial process is stationary. However, before applying the CAR model, the socioeconomic indicators that showed a positive correlation with the average dengue rate through Spearman's coefficient were included in the multiple linear regression model to select variables highly associated with the outcome (Anselim, 2005). The residuals of the multiple linear regression model were analyzed using Moran's Global I to verify if there was spatial autocorrelation. Those with positive spatial autocorrelation were included in the final spatial regression model to analyze the spatial dependence between dengue incidence and socioeconomic indicators. After determining the result of the final spatial regression model, Moran's bivariate $I$ was used to verify the distribution of the spatial dependence of the average dengue incidence rate and the socioeconomic indicators that presented the largest spatial dependence in the regression (Anselim, 2005).

\section{Results}

A total of 63,912 dengue cases were recorded and confirmed in the state of Sergipe. The average incidence rate was 187.2 cases per 100,000 population. Temporal trend analysis demonstrated a heterogeneous pattern with increasing and decreasing incidence over the years. The period from 2006 to 2008 showed a significant and growing trend (AAPC: $423 \% \mathrm{p}<0.01$ ), with the highest dengue epidemic reported in 2008. Subsequently, the incidence decreased to $86 \%$ from 2009 to 2010 compared with that of previous years. A dengue epidemic was also reported in 2012 and 2015 (Figure 2). With regard to the average incidence of dengue in the spatial distribution, a high concentration of dengue cases was distributed diffusely in several regions of the state, with greater intensity in the southeast region. With the rate smoothed by the Bayesian estimator, a low variation was observed and risk clusters were also visualized in the south-eastern region (Figure 3A and B). Moran's $I$ for the corrected average rate was significant for the period analyzed (I: $0.18 ; \mathrm{P}<0.01$ ). The map analysis according to Moran's $I$ allowed the identification of the municipalities classified according to significance level of their local indexes. Three clustered regions were identified: two in the south-eastern and southern regions with high incidence rates $(\mathrm{Q} 1$ : high/high; $\mathrm{P}=0.01)$ and one in the North with the lowest incidence rates (Q2: low/low; $\mathrm{P}=0.001$ ) (Figure $3 \mathrm{C}$ and D). The best indicators of the socioeconomic status showed an inverse correlation with the incidence of dengue. However, indicators related to low education, water supply and inadequate sanitation, low income, and poverty showed a positive correlation with the outcome (Table 1).

Moran's Global I of socioeconomic indicators showing a positive correlation with dengue incidence are shown in Table 2. Spatial autocorrelation was significant for most of the independent variables, particularly for the following variables: percentage of permanent private households in which the head of the household receives up to 2 minimum wages; the percentage of income appropriated by the poorest $80 \%$, percentage of people in households 
vulnerable to poverty and where no one has complete elementary education; the percentage of people in households with inadequate water supply and sanitation; and the percentage of per capita income of the extremely poor.

The inclusion of the spatial component in the regression model was based on two points: 1) the dependent variable had significant spatial autocorrelation; and 2) most of the socioeconomic indicators that showed a positive correlation with dengue incidence showed spatial autocorrelation in the analysis of multiple linear regression residues based on Moran's Global I (Table 3). The linear regression model explains $40 \%$ of the incidence of dengue in the state of Sergipe during the study period $\left(\mathrm{R}^{2}=0.40 / \mathrm{P}<0.001\right)$. The socioeconomic indicators were significantly associated with the average incidence of dengue in the percentage of permanent private households in which the responsible person receives up to 2 minimum wages; the percentage of income appropriated by the poorest $80 \%$, percentage of people in households with inadequate water supply and sewage; and the percentage of extremely poor (Table 4). The spatial regression demonstrated the spatial dependence of the result with some socioeconomic indicators. Thus, the analysis of Moran's bivariate $I$ was used to verify the spatial distribution of the variables percentage of income appropriated by the poorest $80 \%$ and those in households with inadequate supply of water and sewage, since they were more associated with the incidence of dengue in the state. Spatial autocorrelation was positive for dengue incidence and percentage of the extremely poor (I: $0.67 / \mathrm{P}=0.01$ ). The formation of a high-risk cluster in the central region of the state (Q1: high/high; $\mathrm{P}=0.01)$ and a low-risk cluster in the northern region of the state $(\mathrm{Q} 2$ : low/low; $\mathrm{P}=0.01$ ) was observed (Figure $4 \mathrm{~A})$. With regard to the incidence of dengue and percentage of people in households with inadequate water supply and sewage, a positive spatial autocorrelation was also observed (I: $0.56 / \mathrm{P}=0.02$ ). The map revealed low-risk areas in the northern region $(\mathrm{Q} 2$ : low/low; $\mathrm{P}=0.01)$ and diffusely distributed high-risk areas (Q1: high/high; $\mathrm{P}=0.01$ ) highlighting the state capital (Figure 4B).

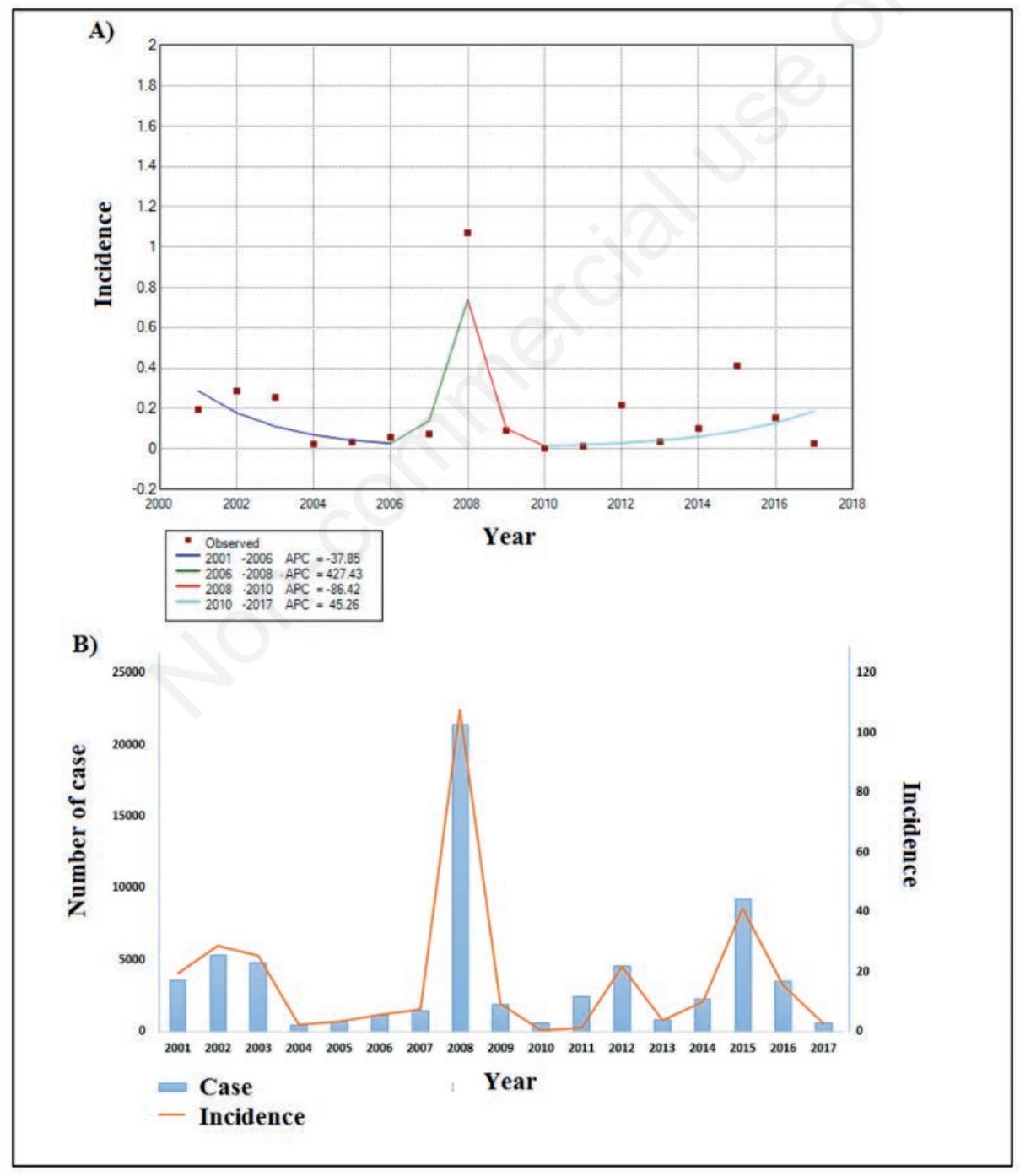

Figure 2. Temporal pattern of dengue incidence from 2000 to 2018 in Sergipe, Brazil. A) Time trend distribution of the average dengue incidence rate and the annual percentage change (AAPC) for each period; B) Ratio of number of dengue cases and average dengue incidence rate. 


\section{Discussion}

Implementation of strategies to reduce dengue morbidity and mortality in endemic areas requires integrated epidemiological information to improve knowledge of factors related to local transmission. In addition, through the current epidemiological framework of emerging arboviruses, integrating epidemiological information and social inequities is essential for preventing epidemics not only of dengue but also of zika and chikungunya as they are transmitted by an Ae. aegypti mosquito (Weaver and Reisen, 2010). Our results indicate that dengue is endemic in the state of Sergipe. The trend was increasing mainly from 2004 to 2008. Subsequently, the incidence of dengue remained stationary, but it became endemic in 2012 and 2015. In 2015, the chikungunya and zika arboviruses were already in circulation in the Brazilian territory triggering epidemics (Marcondes and Ximenes, 2016).

Spatial analysis showed a distinct behavior according to the regions of the state of Sergipe. This finding reflects different risks for the disease, showing high incidence mainly in the north, south, and southeast regions. In addition, it was possible to verify that the disease presents clusters in $90 \%$ of the state with different degrees of risks. The identification of clusters indicated a broader epidemiological view of the areas most at risk of transmission. Spatial analyzes indicated future risks, possibly avoidable, in areas that require further health action and consolidation of surveillance measures. According to the World Health Organization (WHO) health systems need to respond better and faster to the challenges of a changing world (WHO, 2008).

It was possible to identify that the indicators related to low education, water supply and inadequate sanitation, low income, and poverty had a positive correlation with the incidence of the disease. Socioeconomic factors may play a significant role in dengue epidemics (Ren et al., 2015; Lippi et al., 2018). Dengue may be associated with low socioeconomic status, low income, low education, low literacy (Mondini and Chiaravalloti-Neto, 2008; Hagenlocher et al., 2013), lack of knowledge about dengue (Soghaier et al., 2015), pres-

Table 1. Correlation of socioeconomic variables and average dengue incidence rate in Sergipe, Brazil 2000 to 2018.

Percentage of permanent private households where the household head receives more than 10 minimum wages

Social Development Index

$-0.37$

Life expectancy at birth

$-0.42<0.01$

Longevity index

Income per capita

Gini Index

Theíl Index

Percentage of people living alone

$-0.28<0.01$

Percentage of population in households with piped water

Percentage of income appropriated by the richest $20 \%$

Percentage of population in households with toilets and running water

Percentage of population in households who have access to garbage collection services

Percentage of population in households with electricity

Percentage of improvised households

Percentage of permanent private households where the household head receives up to 2 minimum wages

$0.18 \quad 0.02$

Percentage of population in households with a density of $>2$

Percentage illiteracy over 15 years

$0.38<0.01$

Percentage of unemployment for 10 years or more

Percentage of income appropriated by the poorest $80 \%$

0.19

Percentage of income appropriated by the poorest $20 \%$

Percentage of people in households where no one has completed elementary school

Percentage of 15-to-24-year-old individuals who do not study, do not work, and are vulnerable

$0.17 \quad 0.01$

Percentage of people in households who are vulnerable to poverty and where no one has complete fundamental

$\begin{array}{ll}0.19 & 0.08 \\ 0.46 & <0.01\end{array}$

Percentage of vulnerable and elderly dependent

Percentage of people in households without electricity

$0.40<0.01$

Percentage of people in homes with inadequate walls

Percentage of people in households with inadequate water supply and sewage

$0.15 \quad 0.03$

Percentage of extremely poor

$\begin{array}{ll}0.34 & <0.01 \\ 0.38 & <0.01\end{array}$

Percentage of poor

Percentage of individuals vulnerable to poverty

Percentage of per capita income of the extremely poor

$0.25 \quad 0.07$

Percentage of per capita income of the poor

$\begin{array}{lc}0.15 & 0.05 \\ 0.17 & 0.06 \\ 0.53 & <0.01 \\ 0.40 & <0.01 \\ 0.37 & <0.01 \\ 0.38 & <0.01 \\ 0.29 & <0.01 \\ 0.28 & <0.01\end{array}$


ence of economically inactive people at home as unemployed, students and domestic workers (Hagenlocher et al., 2013), crowding of households (Braga et al., 2010), poor housing with sewage and inadequate waste collection (Costa et al., 2013), household density (Khormi and Kumar, 2011), and type of housing as individual house, apartment, or large residential area (Braga et al., 2010). However, other studies found no association between dengue and income or number of people per household (Heukelbach et al., 2001), or concluded that dengue affected groups with high socioeconomic conditions (Seidahmed et al., 2012). These contradictory results occur due

Table 2. Spatial autocorrelation of socioeconomic variables that showed a positive correlation with the average incidence rate of dengue in Sergipe, Brazil 2000 to 2018.

\begin{tabular}{|c|c|c|}
\hline Variable & n's Global $I$ & $P$-value \\
\hline Percentage of improvised households & 0.58 & 0.02 \\
\hline Percentage of permanent private households where the household head receives up to 2 minimum wages & 0.69 & 0.01 \\
\hline Percentage of population in households with a density of $>2$ & 0.47 & 0.01 \\
\hline Percentage illiteracy over 15 years & 0.34 & 0.01 \\
\hline Percentage of unemployment for 10 years or more & 0.29 & 0.03 \\
\hline Percentage of income appropriated by the poorest $80 \%$ & 0.78 & 0.01 \\
\hline Percentage of income appropriated by the poorest $20 \%$ & 0.50 & 0.01 \\
\hline Percentage of people in households where no one has completed elementary school & 0.25 & 0.03 \\
\hline Percentage of 15-to-24-year-old individuals who do not study, do not work, and are vulnerable & 0.24 & 0.01 \\
\hline Percentage of people in households who are vulnerable to poverty and where no one has completed fundamental elementary school & 0.78 & 0.01 \\
\hline Percentage of vulnerable and elderly dependent & 0.35 & 0.07 \\
\hline Percentage of people in households without electricity & 0.45 & 0.02 \\
\hline Percentage of people in homes with inadequate walls & 0.57 & 0.1 \\
\hline Percentage of people in households with inadequate water supply and sewage & 0.73 & 0.01 \\
\hline Percentage of extremely poor & 0.52 & 0.01 \\
\hline Percentage of poor & 0.39 & 0.01 \\
\hline Percentage of individuals vulnerable to poverty & 0.43 & 0.01 \\
\hline Percentage of per capita income of the extremely poor & 0.67 & 0.01 \\
\hline Percentage of per capita income of the poor & 0.52 & 0.01 \\
\hline
\end{tabular}

Table 3. Multiple linear regression and analysis of Global Moran's I of the average dengue incidence rate residues in Sergipe, Brazil 2000 to 2018.

\begin{tabular}{|c|c|c|c|c|c|}
\hline Variable & Coefficient $\left(\mathbf{R}^{2}\right)$ & P-value & $95 \%$ CI & Moran's Global I & $P$-value \\
\hline Percentage of improvised households & 0.28 & 0.05 & $17.1-32.0$ & 0.16 & 0.06 \\
\hline $\begin{array}{l}\text { Percentage of permanent private households where the household } \\
\text { head receives up to } 2 \text { minimum wages }\end{array}$ & 0.58 & $<0.01$ & $39.2-62.9$ & 0.48 & 0.01 \\
\hline Percentage of population in households with a density of $>2$ & 0.49 & 0.01 & $25.0-56.0$ & 0.49 & 0.01 \\
\hline Percentage illiteracy over 15 years & 0.27 & 0.06 & $16.3-31.2$ & 0.19 & 0.09 \\
\hline Percentage of unemployment for $\geq 10$ years & 0.39 & 0.05 & $22.0-42.0$ & 0.19 & 0.09 \\
\hline Percentage of income appropriated by the poorest $80 \%$ & 0.46 & 0.08 & $33.5-55.0$ & 0.55 & 0.01 \\
\hline Percentage of income appropriated by the poorest $20 \%$ & 0.40 & 0.08 & $39.0-54.9$ & 0.50 & 0.01 \\
\hline $\begin{array}{l}\text { Percentage of people in households where no one has completed } \\
\text { elementary school }\end{array}$ & 0.45 & 0.02 & $40.0-47.0$ & 0.22 & 0.08 \\
\hline Percentage of 15-24-years old who do not study, do not work and are vulnerable & 0.54 & $<0.01$ & $35.0-58.0$ & 0.45 & 0.02 \\
\hline $\begin{array}{l}\text { Percentage of people in households who are vulnerable to poverty } \\
\text { and where no one has completed fundamental education }\end{array}$ & 0.50 & $<0.01$ & $48.0-55.0$ & 0.49 & 0.01 \\
\hline Percentage of vulnerable and elderly dependents & 0.15 & 0.09 & $10.0-18.0$ & 0.35 & 0.06 \\
\hline Percentage of people in households without electricity & 0.25 & 0.05 & $20.0-29.0$ & 0.28 & 0.07 \\
\hline Percentage of people in homes with inadequate walls & 0.27 & 0.05 & $23.2-29.9$ & 0.12 & 0.10 \\
\hline Percentage of people in households with inadequate water supply and sewage & 0.62 & $<0.01$ & $58.0-70.0$ & 0.62 & 0.01 \\
\hline Percentage of extremely poor & 0.50 & $<0.01$ & $48.0-55.0$ & 0.59 & 0.01 \\
\hline Percentage of poor & 0.39 & $<0.01$ & $22.0-42.0$ & 0.50 & 0.01 \\
\hline Percentage of vulnerable to poverty & 0.39 & $<0.01$ & $22.0-42.0$ & 0.45 & 0.01 \\
\hline Percentage of per capita income of the extremely poor & 0.40 & $<0.01$ & $39.0-54.9$ & 0.35 & 0.02 \\
\hline Percentage of per capita income of the poor & 0.38 & $<0.01$ & $21.7-50.0$ & 0.40 & 0.02 \\
\hline
\end{tabular}


to the heterogeneity in dengue control measures and the socioeconomic indicators of the analyzed areas (Mulligan et al., 2015), and may be a good explanation of the occurrence of dengue in urban and rural regions with different socioeconomic situations in the state of Sergipe.

Previous studies that demonstrated the relationship of dengue fever with socioeconomic factors mostly assessed the relationship at an individual level. There are few studies that correlate these factors at the ecological level. Thus, in the spatial modelling, we verified that the social inequalities that presented a significant association were as follows: percentage of permanent private

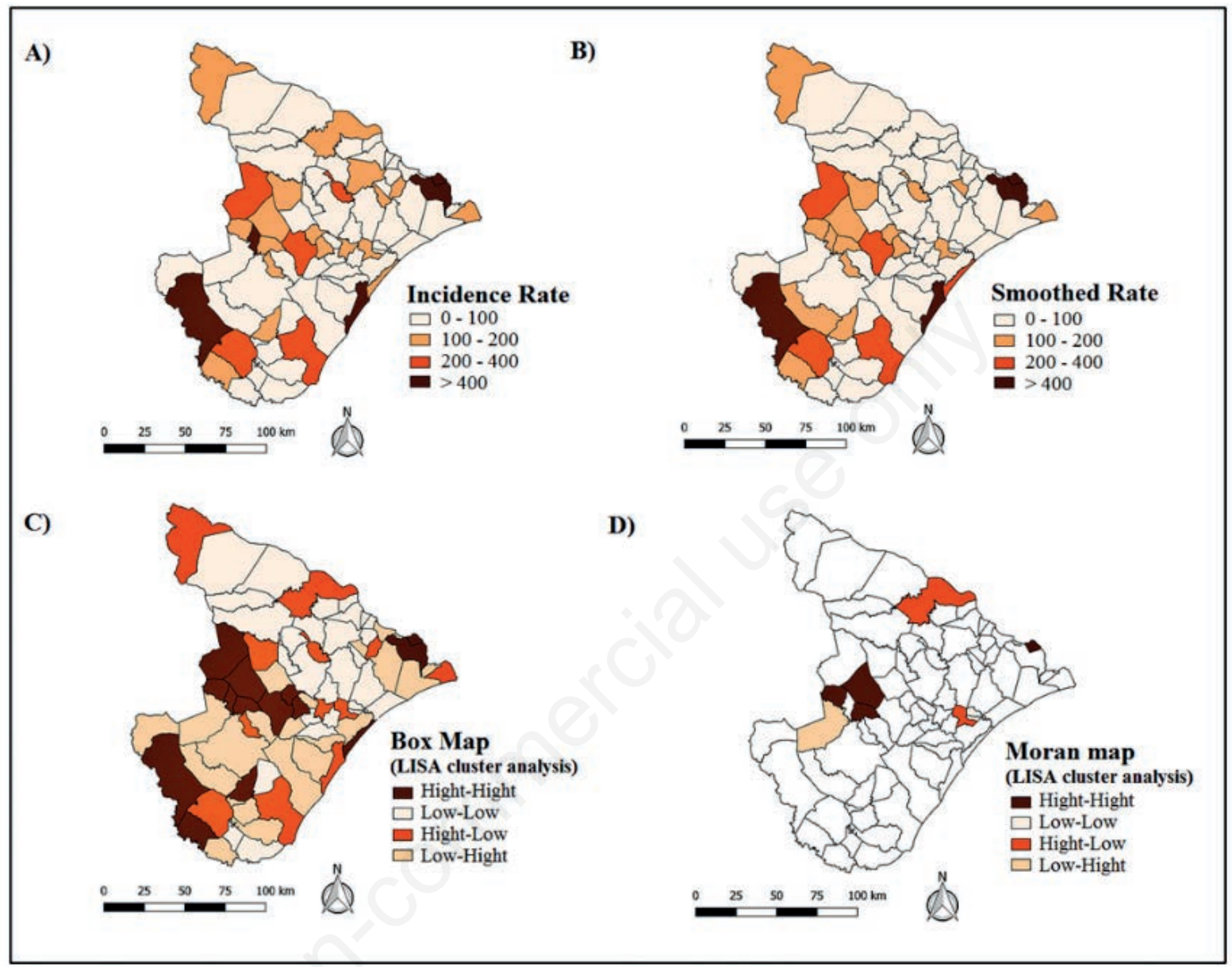

Figure 3. Spatial analysis of the average dengue incidence rate from 2000 to 2018 in Sergipe, Brazil. A) Average incidence rate; B) Global empirical Bayesian rate; C) Spatial clusters demonstrated by Moran's scattering diagram; D) Areas in the state with high incidence of dengue.

Table 4. Final model of spatial regression with mean dengue incidence rate and socioeconomic variables in Sergipe, Brazil 2000 to 2018.

\begin{tabular}{|c|c|c|c|}
\hline Variable & Coefficient & Standard error & $P$-value \\
\hline Percentage of permanent private households where the household head receives up to 2 minimum wages & 0.62 & 0.08 & 0.01 \\
\hline Percentage of population in households with a density of $>2$ & 0.50 & 0.11 & 0.01 \\
\hline Percentage of income appropriated by the poorest $80 \%$ & 0.77 & 0.08 & 0.01 \\
\hline Percentage of income appropriated by the poorest $20 \%$ & 0.68 & 0.07 & 0.01 \\
\hline Percentage of 15-to-24-year-old individuals who do not study, do not work, and are vulnerable & 0.50 & 0.11 & 0.02 \\
\hline Percentage of people in households who are vulnerable to poverty and where no one has complete fundamental & al $\quad 0.50$ & 0.11 & 0.01 \\
\hline Percentage of people in households with inadequate water supply and sewage & 0.72 & 0.07 & 0.01 \\
\hline Percentage of extremely poor & 0.60 & 0.05 & 0.01 \\
\hline Percentage of poor & 0.37 & 0.09 & 0.01 \\
\hline Percentage of vulnerable to poverty & 0.39 & 0.09 & 0.01 \\
\hline Percentage of per capita income of the extremely poor & 0.50 & 0.11 & 0.02 \\
\hline Percentage of per capita income of the poor & 0.28 & 0.15 & 0.02 \\
\hline
\end{tabular}


households in which the responsible person receives up to 2 minimum wage, percentage of income appropriated by the poorest $80 \%$, percentage of people in households with inadequate water supply and sewage, and percentage of extremely poor.

The Sergipe state has high population density, high social inequality rate demonstrated by the Gini index, and inadequate average rate demonstrated by the Human Development index (Lima et al., 2019). These factors contribute to the establishment of inadequate housing, work, and income conditions in different areas, especially those that may have good social development such as the capital, and which favour the risk of dengue disease, as demonstrated in a previous study conducted in a district of the municipality of Aracaju, which identified key properties responsible for maintaining the vector infestation and which are mosquito breeding grounds that can spread to neighbouring areas (Marteis et al., 2013).

Poverty increases the risk of dengue transmission by promoting exposure to risk factors related to dengue transmission, since the vector favours building constructions in urban areas, human agglomeration and a significant increase in population density. Some properties located in the municipalities of Sergipe have con- tainers, such as raised water tanks, tunnels, laundries and fixed tanks, that are important for the proliferation of the vector (Akter et al., 2017). In addition, some regions have inadequate water supply, which triggers the practice of open storage of water for use in domestic activities. This scenario further increases the incidence of dengue in the state and its relationship with the poorer areas.

A systematic review study found that there is no consistent evidence supporting that poverty is a predictor of dengue occurrence (Mulligan et al., 2015). This lack of evidence may also be related to the scale of analysis generally adopted to assess this type of association. Considering dengue persistence on an intra-urban scale can help define a more appropriate scale for measuring the relationship between dengue and socioeconomic conditions, which can also help explore how other systems interact to explain why not all underserved areas have concentrated cases. Previous studies have found positive correlations between lack of basic sanitation services and dengue transmission, as inadequate sanitation and water storage in urban and rural areas favour optimal habitat for breeding and proliferation of Ae. Aegypti mosquitoes (Stewart et al., 2013; Stewart-Ibarra et al., 2014). Although there is evidence that sanitation services reduce the amount of habitat for vector

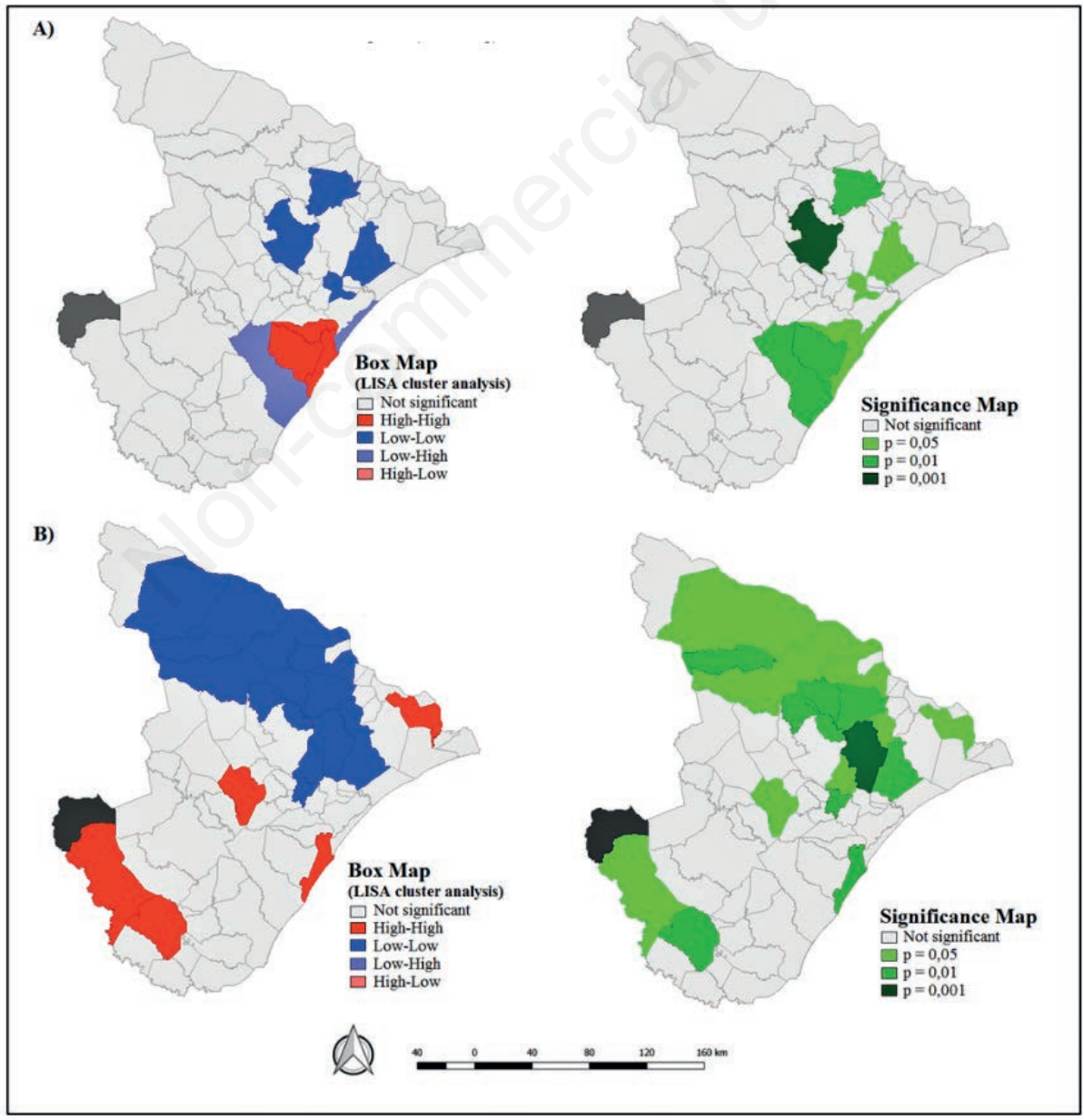

Figure 4. Moran's bivariate analysis between social inequalities and average dengue incidence rate during the period 2000 to 2018 in Sergipe, Brazil. A) Moran's bivariate between the average dengue incidence rate and the extremely poor rate; B) Moran bivariate between average dengue incidence rate and inadequate sanitation. 
development, some evidence suggested that highly urbanized areas provide ample habitat regardless of the availability of these services (Schmidt et al., 2011), demonstrating human action as an important factor.

The social context may undermine the spatial relationships established in this study as regions with higher levels of human development may also have large inequalities. Hence, we believe that the accelerated urbanization in certain cities may enhance the unregulated formation of poverty pockets in the state. In addition, the knowledge and attitudes of the population regarding the maintenance of basic sanitation, home care with good practices that prevent the proliferation of the vector and the use of repellents contribute significantly to reduce the incidence of dengue, especially in places with high population density. However, despite the level of knowledge of the population, the vector may well find breeding sites in homes, showing that even knowing how mosquitoes reproduce may not help. Thus, the population does not always participate with appropriate practices to reduce or eliminate breeding sites, especially not in situations of social vulnerability (Souza et al., 2012). Thus, vector control and health surveillance measures should include guidelines for the population regarding the importance of active participation in the reduction and elimination of breeding sites. In the risk areas identified in this study, it is important that endemic agents and health professionals advise home visits that residents avoid accumulating water and protect storage containers, as well as perform the correct hygiene.

The study has limitations regarding the use of secondary data, since errors may occur in the notification and availability of information. There are also limitations regarding the analysis of ecological characteristics only and not individual characteristics and their risk factors. However, it is believed that the results could bring significant benefits to policy-making with new strategies for control and expansion of intersectoral and health services activities.

\section{Conclusion}

In 2008, the state of Sergipe presented the largest recorded dengue epidemic, followed by two more in 2012 and 2015. Social indicators such as the percentage of income of the extremely poor and inadequate sanitation explain the incidence in the state. Although all municipalities in the state showed a temporal variability among dengue incidence rates during the period analyzed. The regions in the Southeast and South were considered at a particularly high risk for dengue.

\section{References}

Akter R, Naish S, Hu W, Tong S, 2017. Socio-demographic, ecological factors and dengue infection trends in Australia. PLoS ONE 12:e0185551.

Anselim L, 2005. Exploring a spatial data with GeoDaTM: a workbook. Rev. version. Urbana Center for Spatially Integrated Social Science of University of Illinois, USA.

Araújo VEM, Bezerra JMT, Amâncio FF, Passos VMA, Carneiro $\mathrm{M}, 2017$. Increase in the burden of dengue in Brazil and federated units, 2000 and 2015: analysis of the Global Burden of Disease Study 2015. Rev Bras Epidemiol 20:205-16.

Bhatt S, Gething PW, Brady OJ, Messina JP, Farlow AW, Moyes
CL, et al, 2013. The global distribution and burden of dengue. Nature 496:504-7.

Braga C, Luna CF, Martelli CM, de Souza WV, Cordeiro MT, Alexander N, et al, 2010. Seroprevalence and risk factors for dengue infection in socio-economically distinct areas of Recife, Brazil. Acta Trop 113:234-40.

Brasil MS, 2007. Sistemas de Informações Geográficas e Análise Espacial na Saúde Pública. Ministério da Saúde, Ministry of Health, Brazil, 148 pp

Câmara G, Monteiro AMV, 2001. Geocomputation techniques for spatial analysis: are they relevant to health data? CadSaude Publica, Rio Janeiro 17:1059-81.

Christofferson RC, Mores CN, 2015. A role for vector control in dengue vaccine programs. Vaccine 33:7069-74.

Costa JV, Donalisio MR, Silveira LV, 2013. Spatial distribution of dengue incidence and socio-environmental conditions in Campinas, Sao Paulo State, Brazil, 2007. Cad Saude Publica 29:1522-32.

Druck S, Carvalho MS, Câmara G, Monteiro AMV, 2004. [Análise espacial de dados geográficos. Brasília (DF): Empresa Brasileira de Pesquisa Agropecuária (EMBRAPA).] [Article in Portuguese].

Francis S, Saavedra-Rodriguez K, Perera R, Paine M, Black WC IV, Delgoda R, 2017. Insecticide resistance to permethrin and malathion and associated mechanisms in Aedes aegypti mosquitoes from St. Andrew Jamaica. PLoS ONE 12: 0179673 .

Frenk J, Moon S, 2013. Governance challenges in global health. N Engl J Med 368:936-42.

Guo XX, Zhu XJ, Li CX, 2013. Vector competence of Aedes albopictus and Aedes aegypti (Diptera: Culicidae) for Den 243 and New Guinea $C$ virus strains of dengue 2 virus. Acta Trop 128:566-70.

Hagenlocher M, Delmelle E, Casas I, Kienberger S, 2013. Assessing socioeconomic vulnerability to dengue fever in Cali, Colombia: statistical vs expert-based modelling. Int J Health

Geogr 12:36. doi: 10.1186/1476-072X-12-36.

Heukelbach J, de Oliveira FA, Kerr-Pontes LR, Feldmeier H, 2001. Risk factors associated with an outbreak of dengue fever in a favela in Fortaleza, north-east Brazil. Trop Med Int Health 6:635-42.

Instituto Brasileiro de Geografia e Estatística (IBGE). Brasil, 2017. Available from: http://cidades.ibge.gov.br/xtras/uf.php? $\operatorname{coduf}=28$.

Khormi HM, Kumar L, 2011. Modelling dengue fever risk based on socioeconomic parameters, nationality and age groups: GIS and remote sensing-based case study. Sci Total Environ 409:4713-9.

Kim H, Fay MP, Feuer EJ, Midthune DN, 2000. Permutation tests for joinpoint regression with applications to cancer rates. Stat Med 19:335-51.

Lima SVMA, Santos AD, Duque AM, Oliveira-Goes MA, Silva MVP, Araújo DC, et al, 2019. Spatial and temporal analysis of tuberculosis in an area of social inequality in Northeast Brazil. BMC Public Health 873:19. doi: 10.1186/s12889-019-7224-0.

Lippi CA, Stewart-Ibarra AM, Muñoz ÁG, et al, 2018. The social and spatial ecology of dengue presence and burden during an outbreak in Guayaquil, Ecuador, 2012. Int J Environ Res Public Health 15:E827.

Lutomiah J, Barrera R, Makio A, Mutisya J, Koka H, Owaka S, et al., 2016 Dengue Outbreak in Mombasa City, Kenya, 20132014: Entomologic Investigations. PLoS Negl Trop Dis 
10:e0004981. doi: 10.1371/journal.pntd.0004981

Marcondes CB, Ximenes MFFM, 2016. Zika virus in Brazil and the danger of infestation by Aedes (Stegomyia) mosquitoes. Rev Soc Bras Med Trop 49:4-10.

Marteis LS, Stefller LM, Araújo KCGM, Santos RLC, 2013. [Identificação e distribuição espacial de imóveischave de Aedes aegypti no bairro Porto Dantas, Aracaju, Sergipe, Brasil entre 2007 e 2008.] Cad Saúde Pública, Rio de Janeiro 29:36878. [Article in Portuguese].

Mondini A, Chiaravalloti-Neto F, 2008. Spatial correlation of incidence of dengue with socioeconomic, demographic and environmental variables in a Brazilian city. Sci Total Environ 393:241-8.

Moran PAP, 1948. The interpretation of statistical maps. J R Stat Soc Ser B 10: 243-251.

Moyes CL, Vontas J, Martins AJ, Ng LC, Koou SY, Dusfour I, et al, 2017. Contemporary status of insecticide resistance in the major Aedes vectors of arboviruses infecting humans. PLoS Negl Trop Dis 11:e0005625.

Mulligan K, Dixon J, Joanna Sinn CL, Elliott SJ, 2015. Is dengue a disease of poverty? A systematic review. Pathog Glob Health 109:10-8.

Ren H, Ning W, Lu L, Zhuang D, Liu Q, 2015. Characterization of dengue epidemics in mainland China over the past decade. J Infect Dev Ctries 9:970-6.

Restrepo BN, Beatty ME, Goez Y, Ramirez RE, Diaz FJ, Piedrahita LD et al, 2014. Frequency and clinical manifestations of dengue in urban Medellin, Colombia. J Trop Med 872608. doi: $10.1155 / 2014 / 872608$.

Schmidt WP, Suzuki M, Dinh Thiem V, White RG, Tsuzuki A, Yoshida LM, et al, 2011. Population density, water supply, and the risk of dengue fever in Vietnam: Cohort study and spatial analysis. PLoS Med 8:e1001082.

Seidahmed OM, Hassan SA, Soghaier MA, Siam HA, Ahmed FT, Elkarsany MM, et al, 2012. Spatial and temporal patterns of dengue transmission along a Red Sea coastline: a longitudinal entomological and serological survey in Port Sudan city. PLoS Negl Trop Dis 6:e1821.

Sergipe. State Secretariat of Health, 2011. A sanitary and managerial reform of the SUS in the state of Sergipe: knowledge and technologies to implement a policy. Apprentice's Book 1.

Soghaier MA, Himatt S, Osman KE, Okoued SI, Seidahmed OE,
Beatty ME, et al, 2015. Cross-sectional community-based study of the socio-demographic factors associated with the prevalence of dengue in the eastern part of Sudan in 2011. BMC Public Health 15:558. doi: 10.1186/s12889-015-1913-0.

Souza VMM, Hoffmann JL, Freitas MM, Brant JL, Araújo WN, 2012. [Avaliação do conhecimento, atitudes e práticas sobre dengue no Município de Pedro Canário, Estado do Espírito Santo, Brasil, 2009: um perfil ainda atual.] Rev Pan-Amaz Saude 3:37-43. [Article in Portuguese].

Stewart-Ibarra AM, Muñoz ÁG, Ryan SJ, Ayala EB, BorborCordova MJ, Finkelstein JL, et al, 2014. Spatiotemporal clustering, climate periodicity, and social-ecological risk factors for dengue during an outbreak in Machala, Ecuador, in 2010. BMC Infect Dis 14:610. doi: 10.1186/s12879-014-0610-4.

Stewart-Ibarra AM, Ryan SJ, Beltrán E, Mejía R, Silva M, Muñoz Á, 2013. Dengue vector dynamics (Aedes aegypti) influenced by climate and social factors in Ecuador: Implications for targeted control. PLoS ONE 8:e78263.

Stewart-Ibarra AM, Ryan SJ, Kenneson A, King CA, Abbott M, Barbachano-Guerrero A, et al, 2018. The burden of dengue fever and chikungunya in southern coastal Ecuador: epidemiology, clinical presentation, and phylogenetics from the first two years of a prospective study. Am J Trop Med. Hyg 98:1444-1459. doi: 10.4269/ajtmh.17-0762.

United Nations Development Program, 2010. [Programa das Nações Unidas para o Desenvolvimento.] Accessed: 01 January 2020. Available from: https://www.br.undp.org/ [Website in Portuguese].

Vazquez-Prokopec GM, Kitron U, Montgomery B, Horne P, Ritchie SA, 2010. Quantifying the spatial dimension of dengue virus epidemic spread within a tropical urban environment. PLoS Negl Trop Dis 4:e920.

Weaver SC, Reisen WK, 2010. Present and future arboviral threats. Antiviral Res 85:328-45.

WHO, 2008. The world health report 2008: primary health care now more than ever. Available from: https:/www.who.int/whr/ 2008/en/ (accessed April 2020)

WHO, 2015. Dengue and dengue haemorrhagic fever. Fact sheet no. 117.

Zara ALSA, Santos SM, Fernandes-Oliveira ES, Carvalho RG, Coelho GE, 2016. Aedes aegypti control strategies: a review. Epidemiologia e Serviços de Saúde 25:391-404. 